\title{
Fluoroquinolone therapy and idiosyncratic acute liver injury: a population-based study
}

\author{
J. Michael Paterson MSc, Muhammad M. Mamdani PharmD MPH, Michael Manno MSc, \\ David N. Juurlink MD PhD; for the Canadian Drug Safety and Effectiveness Research Network
}

See related commentary by Hayashi and Chalasani on page 1555 and at www.cmaj.ca/lookup/doi/10.1503/cmaj.121270

\begin{abstract}
Background: Although fluoroquinolones are sometimes associated with mild, transient elevations in aminotransferase levels, serious acute liver injury is uncommon. Regulatory warnings have identified moxifloxacin as presenting a particular risk of hepatotoxicity. Thus, we examined the risk of idiosyncratic acute liver injury associated with the use of moxifloxacin relative to other selected antibiotic agents.
\end{abstract}

Methods: We conducted a population-based, nested, case-control study using health care data from Ontario for the period April 2002 to March 2011. We identified cases as outpatients aged 66 years or older with no history of liver disease, and who were admitted to hospital for acute liver injury within 30 days of receiving a prescription for 1 of 5 broadspectrum antibiotic agents: moxifloxacin, levofloxacin, ciprofloxacin, cefuroxime axetil or clarithromycin. For each case, we selected up to 10 age- and sex-matched controls from among patients who had received a study antibiotic, but who were not admitted to hos- pital for acute liver injury. We calculated odds ratios (ORs) to determine the association between admission to hospital and previous exposure to an antibiotic agent, using clarithromycin as the reference.

Results: A total of 144 patients were admitted to hospital for acute liver injury within 30 days of receiving a prescription for one of the identified drugs. Of these patients, $88(61.1 \%)$ died while in hospital. After multivariable adjustment, use of either moxifloxacin (adjusted OR 2.20, 95\% confidence interval [Cl] 1.21-3.98) or levofloxacin (adjusted OR 1.85, 95\% Cl 1.01-3.39) was associated with an increase in risk of acute liver injury relative to the use of clarithromycin. We saw no such risk associated with the use of either ciprofloxacin or cefuroxime axetil.

Interpretation: Among older outpatients with no evidence of liver disease, moxifloxacin and levofloxacin were associated with an increased risk of acute liver injury relative to clarithromycin.
Competing interests: J. Michael Paterson, Michael Manno and David Juurlink received salary support from the Institute for Clinical Evaluative Sciences, a nonprofit research institute funded by the Ontario Ministry of Health and Long-Term Care. Muhammad Mamdani has served on advisory boards or as a consultant for Hoffmann-La Roche, GlaxoSmithKline, Pfizer, Novartis, Lilly, Astra Zeneca, Boehringer Ingelheim, Bristol-Myers Squibb and Novo Nordisk. No other competing interests were declared.

This article has been peer reviewed.

Correspondence to: David N. Juurlink, dnj @ices.on.ca

CMAJ 2012. DOI:10.1503 /cmaj.111823
$\mathrm{F}$ luoroquinolones are among the most widely prescribed antibiotic agents in North America, and the use of broadspectrum fluoroquinolones such as levofloxacin and moxifloxacin is increasing. ${ }^{1,2}$ Despite their popularity, safety concerns have led to the restriction and, in some cases, withdrawal of several members of this class of drugs, including temafloxacin (owing to hemolysis, renal failure and hypoglycemia), ${ }^{3}$ grepafloxacin (owing to QT interval prolongation), ${ }^{4}$ trovafloxacin (owing to hepatotoxicity $)^{5}$ and, most recently, gatifloxacin (owing to dysglycemia). ${ }^{6}$ The varied and unpredictable nature of these adverse reactions has led to the ongoing scrutiny of the entire class of drugs.

Although fluoroquinolones are occasionally associated with mild, transient elevations in aminotransferase levels, serious acute liver injury is uncommon (estimated at $<10$ per million exposures). ${ }^{7}$ Spontaneous reports and casenoncase analyses suggest wide variation in the risk of acute liver injury among individual fluoroquinolones, ranging from fewer than 1 per million prescriptions for levofloxacin and moxifloxacin to 6 per million prescriptions for trovafloxacin.? In a recent review of the safety of moxifloxacin, the European Medicines Agency raised concerns about potential hepatotoxicity, calling for both stronger warnings and restriction of its use in the treatment of communityacquired pneumonia. ${ }^{8}$ Shortly thereafter, Health Canada issued a warning regarding the risk of moxifloxacin-associated liver injury. ${ }^{9}$

Despite the widespread use of fluoroquinolones, there are few published epidemiologic studies of their safety. Thus, we conducted a population-based, nested, case-control study to explore the association of fluoroquinolone use 
with subsequent admission to hospital for acute hepatotoxicity. Because of recent regulatory warnings regarding moxifloxacin, we thought that admission to hospital for hepatotoxicity would be more likely following treatment with this agent than with other popular broadspectrum antibiotic agents, including other commonly used fluoroquinolones.

\section{Methods}

\section{Setting and design}

We developed a case-control study to examine drug use and clinical outcomes in a cohort of Ontario outpatients aged 66 years or older who had received broad-spectrum antibiotic agents that are frequently used to treat respiratory tract infections. All of the patients have universal access to hospital care, physicians' services and prescription drugs. The study was approved by the Research Ethics Board at Sunnybrook Health Sciences Centre (Toronto, Ontario) and was performed at the Institute for Clinical Evaluative Sciences.

\section{Sources of data}

We identified prescription records using the Ontario Drug Benefit Database, which contains comprehensive records of outpatient prescription medications dispensed to residents of Ontario aged 65 years and older. We identified hospital visits using the Canadian Institute for Health Information Discharge Abstract Database, which contains detailed diagnostic and procedural information regarding all admissions to acute care hospitals in Ontario. We used the Ontario Health Insurance Plan (OHIP) Database to identify paid claims for inpatient and outpatient physician services. We obtained demographic information from the OHIP Registered Persons Database. Finally, we estimated socioeconomic status by linking each patient's residential postal code to the corresponding neighbourhood median household income according to Statistics Canada. ${ }^{10}$ These datasets are linked in an anonymous fashion using encrypted health insurance numbers, they have little missing information, ${ }^{11,12}$ and they are routinely used to study drug safety. ${ }^{13-15}$

\section{Identification of cases and controls}

We defined cases as admissions to hospital for acute liver injury between Apr. 1, 2002, and Mar. 31,2011 . We restricted our analysis to patients admitted within 30 days after receiving a prescription for 1 of 5 commonly used antibiotic agents: clarithromycin, cefuroxime, moxifloxacin, levofloxacin or ciprofloxacin. Hospital admissions for hepatotoxicity were identified using the Canadian enhancement to the International Statistical Classification of Diseases and Related Health Problems, 10th Revision (ICD10-CA) codes for primary and secondary preadmission diagnoses of toxic liver disease (with hepatitis [K71.2, K71.6], hepatic necrosis [K71.1] or unspecified [K71.9]) or acute/subacute or unspecified hepatic failure (K72.0, K72.9) ${ }^{16}$ We selected these codes because previous work suggested they had a high positive predictive value $(95 \%)$ for drug-induced hepatotoxicity. ${ }^{17}$ The date of admission served as the index date for all analyses. For patients with multiple admissions, only the first was included.

For each case, we randomly selected up to 10 controls from the population of patients who received 1 of the 5 antibiotic agents, but who were not admitted to hospital for acute liver injury. We randomly assigned the controls' index dates and, after applying our exclusion criteria, matched them to cases according to age (within $1 \mathrm{yr}$ ) and sex, and to within 90 days of their corresponding case's index date. When fewer than 10 controls could be matched to a case, we used only the controls who could be matched and did not alter the matching algorithm. Cases could serve as controls before becoming a case, but controls could serve as controls only once.

We excluded patients during their first year of eligibility for prescription drug insurance (age $65 \mathrm{yr}$ ) to avoid incomplete medication records in our analysis. We also excluded patients who received multiple study antibiotics in the 30 days before the index date, as well as those admitted to hospital in the 90 days before the index date, to avoid the possible confounding effects of recent illness and misclassification of exposure status due to lack of prescription records for inpatients. Finally, to limit our analyses to patients with no history of liver disease, we excluded patients with any hospital admission, physician service claim or procedure related to liver disease in the preceding 5 years (Appendix 1, available at www.cmaj.ca /lookup/suppl/doi:10.1503/cmaj.111823/-/DC1).

\section{Statistical analysis}

Our primary analysis examined the association between exposure to moxifloxacin and subsequent admission to hospital for acute liver injury. To contextualize our results, we conducted similar analyses for levofloxacin, ciprofloxacin and the second-generation cephalosporin cefuroxime axetil. We used clarithromycin as the reference group for all analyses, because although it has similar clinical indications to fluoroquinolones, it is not generally implicated as a cause of idiosyncratic liver injury. 
We used multivariable logistic regression conditioned on the matched sets to estimate odds ratios (ORs) and 95\% confidence intervals (CIs) for the association between hospital treatment for hepatotoxicity and recent exposure to one of the antibiotic agents we were studying. Potential confounding factors, such as previous use of health services for alcohol dependence, diabetes mellitus, recent use of other hepatotoxic drugs (phenytoin, isoniazid, amoxicillin/clavulanate and valproic acid), ${ }^{18,19}$ residence in a long-term care facility, number of visits to a physician as an outpatient during the preceding year, socioeconomic status and number of prescription drugs received in the preceding year (a validated index of comorbidity) ${ }^{20}$ were entered into the model if differences between cases and controls on bivariate analysis exceeded $p$ less than 0.1 . To assess the potential for residual confounding, we performed a sensitivity analysis in which we excluded residents of long-term care facilities and, by extension, unmeasured factors associated with such care.

Finally, in a supplementary analysis, we estimated the crude incidence of acute liver injury during treatment with one of the antibiotic agents under study by identifying all residents of Ontario aged 66 years or older who received one of these agents during the study period, applying our exclusion criteria and determining the number of patients admitted to hospital with acute hepatotoxicity within 30 days after the drug was dispensed. For those who had multiple prescriptions for antibiotic agents during the study period, each course of treatment was considered separately.

All analyses used a 2-sided type I error rate of 0.05 as the threshold for statistical significance.

\section{Results}

During the study period, we identified 746 patients admitted to hospital for acute hepatotoxicity within 30 days after outpatient treatment with one of the study drugs. Of these patients, 30 $(4.0 \%)$ received multiple study drugs during the 30 -day window, $490(65.7 \%)$ had a diagnosis or procedure related to liver disease in the preceding 5 years, and $82(11.0 \%)$ had been admitted to hospital in the preceding 90 days. The remaining 144 patients were our cases and were matched to 1409 controls.

The mean age of patients in the case group was 77.4 (standard deviation [SD] 7.9) years, and the mean age for controls was 77.0 (SD 7.5 ) years (Table 1). Women accounted for $47.2 \%$ of cases and $47.9 \%$ of controls. Patients in the case group had a relatively higher number of visits to physicians and received more pre- scriptions for drugs in the preceding year, had lower socioeconomic status, were more likely to have diabetes, and were more likely to have been recently exposed to sulfamethoxazole, trimethoprim and drugs with known hepatotoxicity than patients in the control group (Table 1). Among cases, the median time from the dispensing of the antibiotic agent to admission to hospital for acute liver injury was 9 (interquartile range [IQR] 3-19) days, and the median length of stay in hospital was 8 (IQR 4-16) days (data not

\begin{tabular}{|c|c|c|c|}
\hline \multirow[b]{2}{*}{ Characteristic } & \multicolumn{2}{|c|}{$\begin{array}{l}\text { No. }(\%) \text { of patients } \\
\text { or mean } \pm \text { SD }\end{array}$} & \multirow[b]{2}{*}{$p$ value* } \\
\hline & $\begin{array}{c}\text { Cases } \\
n=144\end{array}$ & $\begin{array}{l}\text { Controls } \\
n=1409\end{array}$ & \\
\hline Age, yr & $77.4 \pm 7.9$ & $77.0 \pm 7.5$ & 0.6 \\
\hline $66-75$ & $65(45.1)$ & $654(46.4)$ & 0.9 \\
\hline $76-85$ & $54(37.5)$ & $534(37.9)$ & \\
\hline$\geq 86$ & $25(17.4)$ & $221(15.7)$ & \\
\hline Female sex & $68(47.2)$ & $671(47.6)$ & \\
\hline \multicolumn{4}{|c|}{ Study antibiotic received during the $30-\mathrm{d}$ period before admission } \\
\hline Clarithromycin (reference) & $27(18.8)$ & $431(30.6)$ & 0.03 \\
\hline Cefuroxime axetil & $14(9.7)$ & $141(10.0)$ & \\
\hline Ciprofloxacin & $54(37.5)$ & $483(34.3)$ & \\
\hline Levofloxacin & $23(16.0)$ & $180(12.8)$ & \\
\hline Moxifloxacin & $26(18.1)$ & $174(12.3)$ & \\
\hline $\begin{array}{l}\text { Any study antibiotic received } \\
31-365 \mathrm{~d} \text { before admission }\end{array}$ & $70(48.6)$ & $655(46.5)$ & 0.6 \\
\hline \multicolumn{4}{|l|}{ Neighbourhood income quintile } \\
\hline 1 (lowest) & $21(14.6)$ & $285(20.2)$ & 0.06 \\
\hline 2 & $42(29.2)$ & $303(21.5)$ & \\
\hline 3 & $36(25.0)$ & $280(19.8)$ & \\
\hline 4 & $24(16.6)$ & $288(20.4)$ & \\
\hline 5 (highest) & 20 (13.9) & $246(17.5)$ & \\
\hline Resident in a nursing home & $20(13.9)$ & $162(11.5)$ & 0.4 \\
\hline $\begin{array}{l}\text { No. of prescription drugs received } \\
\text { in the preceding year }\end{array}$ & $14.1 \pm 6.7$ & $12.0 \pm 6.1$ & $<0.001$ \\
\hline $\begin{array}{l}\text { No. of outpatient visits to a physician } \\
\text { in the preceding year }\end{array}$ & $15.7 \pm 11.0$ & $13.4 \pm 9.9$ & 0.009 \\
\hline Diabetes mellitus & $53(36.8)$ & $405(28.7)$ & 0.04 \\
\hline Alcohol dependence & $6(4.2)$ & $30(2.1)$ & 0.1 \\
\hline $\begin{array}{l}\text { Receipt of sulfamethoxazole- } \\
\text { trimethoprim in the } 90 \text {-d period } \\
\text { before admission }\end{array}$ & $9(6.3)$ & $42(3.0)$ & 0.04 \\
\hline $\begin{array}{l}\text { Receipt of allopurinol in the } 90 \text {-d } \\
\text { period before admission }\end{array}$ & $9(6.3)$ & $52(3.7)$ & 0.1 \\
\hline $\begin{array}{l}\text { Receipt of a hepatotoxic drug in the } \\
90-d \text { period before admissiont }\end{array}$ & $8(5.6)$ & $40 \quad(2.8)$ & 0.07 \\
\hline $\begin{array}{l}\text { Note: } S D=\text { standard deviation. } \\
{ }^{*} \chi^{2} \text { or } t \text { test, as appropriate. } \\
\text { tlsoniazid, phenytoin, amoxicillin-clavulanate }\end{array}$ & roate. & & \\
\hline
\end{tabular}


shown). Eighty-eight patients (61.1\%) died during their index admission to hospital (data not shown).

Compared with clarithromycin, moxifloxacin was associated with a more than 2-fold increased risk of admission to hospital for acute liver injury (adjusted OR 2.20, 95\% CI 1.213.98) (Table 2). Levofloxacin was associated with a statistically significant but lower risk of hepatotoxicity than we saw with moxifloxacin (adjusted OR 1.85, 95\% CI 1.01-3.39). In contrast, we saw lower risks with ciprofloxacin and cefuroxime axetil, which did not differ significantly from clarithromycin (Table 2). After we adjusted for other potential confounders, only lower median household income (quintiles 2 and 3) was independently associated with increased risk of acute liver injury (data not shown).

To test the robustness of our conclusions, we excluded residents of long-term care facilities, because these patients were older and systematically different from the rest of our cohort. In this analysis, we found a marginally stronger association between the risk of acute liver injury and

Table 2: Association between admission to hospital for acute liver injury and recent use of antibiotic agents

\begin{tabular}{|lccc|}
\hline Antibiotic agent & $\begin{array}{c}\text { Crude OR } \\
(95 \% \mathrm{Cl})\end{array}$ & $\begin{array}{c}\text { Adjusted OR* } \\
(95 \% \mathrm{Cl})\end{array}$ & p valuet \\
\hline $\begin{array}{l}\text { Clarithromycin } \\
\text { (reference) }\end{array}$ & 1.00 & 1.00 & \\
\hline $\begin{array}{l}\text { Cefuroxime axetil } \\
\text { Ciprofloxacin }\end{array}$ & $1.65(0.84-3.24)$ & $1.43(0.72-2.83)$ & 0.3 \\
\hline $\begin{array}{l}\text { Levofloxacin } \\
\text { Moxifloxacin }\end{array}$ & $2.06(1.12-2.98)$ & $1.56(0.95-2.58)$ & 0.08 \\
\hline $\begin{array}{l}\text { Note: Cl }=\text { confidence interval, OR =odds ratio } \\
\text { *Model includes neighbourhood income quintile, number of prescription drugs received in } \\
\text { the preceding year, number of outpatient visits to a physician in the preceding year, diabetes } \\
\text { mellitus, receipt of sulfamethoxazole and trimethoprim in the 90 days before admission, and } \\
\text { receipt of isoniazid, phenytoin, amoxicillin/clavulanate or valproate in the } 90 \text { days before } \\
\text { admission. } \\
\text { tWald } \chi^{2} \text {. }\end{array}$ & $1.85(1.01-3.39)$ & 0.046 \\
\hline
\end{tabular}

Table 3: Crude incidence of admission to hospital for acute liver injury within 30 days of exposure to an antibiotic agent

\begin{tabular}{|c|c|c|c|}
\hline Antibiotic agent & $\begin{array}{l}\text { No. of } \\
\text { exposures }\end{array}$ & $\begin{array}{l}\text { Admission to } \\
\text { hospital for acute } \\
\text { liver injury within } \\
30 \mathrm{~d} \text { of dispensing }\end{array}$ & $\begin{array}{c}\text { Rate per } 100000 \\
\text { exposures }\end{array}$ \\
\hline $\begin{array}{l}\text { Clarithromycin } \\
\text { (reference) }\end{array}$ & 910817 & 36 & 3.95 \\
\hline Cefuroxime axetil & 248458 & 16 & 6.44 \\
\hline Ciprofloxacin & 1051959 & 67 & 6.37 \\
\hline Levofloxacin & 324660 & 28 & 8.62 \\
\hline Moxifloxacin & 325920 & 26 & 7.98 \\
\hline
\end{tabular}

exposure to moxifloxacin (adjusted OR 2.74, 95\% CI 1.42-5.29) and levofloxacin (adjusted OR $2.29,95 \%$ CI $1.17-4.46]$.

In total, about 2.86 million courses of antibiotic therapy were associated with 172 admissions to hospital for acute liver injury (some of the 144 cases were admitted more than once), or about 6 admissions per 100000 exposures (data not shown). Consistent with the results of our case-control analysis, the crude incidences for admission to hospital with acute liver injury for moxifloxacin (7.98 per 100000 exposures) and levofloxacin (8.62 per 100000 exposures) were about double that associated with clarithromycin (3.95 per 100000 exposures) (Table 3).

\section{Interpretation}

Using the administrative health records of more than 1.5 million older residents of Ontario, we found that, relative to clarithromycin, both moxifloxacin and levofloxacin were associated with almost twice the risk of admission to hospital for acute liver injury among patients with no history of liver disease. Despite recent regulatory warnings regarding the hepatic safety of moxifloxacin, ${ }^{8,9}$ there is a lack of controlled studies supporting the notion that moxifloxacin presents a particular risk relative to other broad-spectrum antibiotic agents and, in particular, to other fluoroquinolones. ${ }^{7-9,21,22}$ Our findings make an important contribution to an evidence base that is currently limited to case reports and registries of drug-induced liver injury. ${ }^{19,23-26}$

Almost two-thirds of the patients in our case group filled their prescriptions in the 2 weeks before they were admitted to hospital, which is consistent with the rapid onset of liver injury reported in most published cases of fluoroquinolone-associated hepatotoxicity. ${ }^{23-26}$ Although the precise mechanism of injury is unknown in our patients' cases, the latency period is consistent with many hypersensitivity reactions to drugs. ${ }^{25,27}$ In our study, more than one-third of patients in the case group were admitted to hospital within 4 days of receiving a prescription for an antibiotic agent. The relatively high case fatality in our study (61.1\% during the index admission to hospital) may be due to our requirement that cases be admitted to hospital. However, given the sources of our data, we cannot be certain that fulminant liver failure was the cause of death for these patients.

Whether chronic liver disease increases a patient's risk for drug-induced liver injury is unknown. However, preexisting liver disease is thought to put patients at risk for a more complicated course and poorer outcomes after such 
injuries..$^{28-30}$ In previous studies, factors such as female sex, diabetes mellitus, chronic alcohol dependence and HIV infection have shown inconsistent associations with drug-induced liver injury. ${ }^{30}$ The American Drug-Induced Liver Injury Network has included 4 hepatotoxic medications in its registry: isoniazid, phenytoin, amoxicillin/clavulanate and valproate. ${ }^{18}$ In our secondary analysis, none of these frequently cited risk factors were associated with acute hepatotoxicity. These results are important, because few previous studies of drug-induced liver injury have included controls or adjusted for potential confounders.

Our overall crude incidence rate of 6 admissions to hospital for acute liver injury per 100000 antibiotic exposures is considerably higher than previously published rates, which are about 1 per 100000 exposures. ${ }^{7}$ Among other factors, our results may be due to differences in definitions of outcomes, incomplete reporting of adverse events in previous studies or the older age of our study's participants placing them at higher risk. ${ }^{30}$

\section{Limitations}

We used administrative data and had no information regarding liver function, actual medication consumption, use of nonprescription drugs or cause of death. Infection itself may predispose a person to liver disease, and our findings could be due to the use of moxifloxacin in patients who are particularly ill. However, confounding by indication is unlikely to fully explain our results. Both moxifloxacin and levofloxacin were associated with a similar risk of acute liver injury, and both drugs are used for indications similar to those for clarithromycin, our drug of reference. Furthermore, excluding residents of long-term care facilities increased the relative risk of liver injury associated with both moxifloxacin and levofloxacin, suggesting that residual confounding is unlikely to fully explain the increased risk.

We excluded patients with evidence of preexisting liver disease and attempted to control for the most frequently cited nongenetic risk factors for drug-induced liver injury, such as diabetes, alcohol dependence and use of hepatotoxic drugs. Although we were unable to control for genetic susceptibility, this is an incompletely understood issue for most drugs - any predisposition would be equally distributed among the drugs we studied. Finally, although the accuracy of hospital discharge coding for acute hepatotoxicity is not well characterized in our particular setting, the ICD10-CA codes we used did well in a study of acetaminophen- induced hepatotoxicity. ${ }^{17}$ In addition, these limitations apply equally to all of the antibiotic agents we studied.

Although our study period largely predates regulatory warnings regarding the hepatic safety of moxifloxacin, some clinicians may have been aware of the earliest warnings, which could theoretically bias outcome determination. Differential outcome determination among patients given moxifloxacin is unlikely to affect our results, however, because liver biochemistry is routinely measured in older patients who present to hospital. Moreover, such a bias would not explain the elevated risk of acute liver injury associated with levofloxacin, for which regulatory warnings were not issued.

Our analysis focused only on patients admitted to hospital, excluding less severe cases of hepatotoxicity managed in emergency departments and other ambulatory care settings. Consequently, we may have underestimated the broader clinical consequences of this rare but important adverse reaction.

Finally, our results derive from data from patients aged 66 years or older. Their experiences may not reflect those of younger patients who may be more prone to purely idiosyncratic drug-induced liver injury. ${ }^{30}$

\section{Conclusion}

Relative to the use of clarithromycin, the use of moxifloxacin and levofloxacin was associated with an increase (about 2-fold) in the risk of admission to hospital for acute liver injury among the patients in our cohort. Similar risks were not seen with the use of ciprofloxacin or cefuroxime axetil. Although our results require confirmation in other settings, they suggest that both moxifloxacin and levofloxacin be considered for regulatory warnings regarding acute liver injury.

\section{References}

1. Linder JA, Huang ES, Steinman MA, et al. Fluoroquinolone prescribing in the United States: 1995 to 2002. Am J Med 2005;118: 259-68.

2. Glass SK, Pearl DL, McEwen SA, et al. A province-level risk factor analysis of fluoroquinolone consumption patterns in Canada (2000-06). J Antimicrob Chemother 2010;65:2019-27.

3. Recalling the Omniflox (temafloxacin) tablets [news release]. Silver Spring (MD): US Food and Drug Administration; 1992 Available: www.fda.gov/ohrms/dockets/ac/98/briefingbook/1998 -3454B1_03_WL49.pdf (accessed 2010 Nov. 25).

4. Kent RS. Withdrawal of product: RAXAR (grepafloxacin $\mathrm{HCl}$ ) $600 \mathrm{mg}$ tablets, $400 \mathrm{mg}$ tablets, and $200 \mathrm{mg}$ tablets [letter from Glaxo Wellcome]. Silver Spring (MD): US Food and Drug Administration; 1999. Available: www.fda.gov/ohrms/dockets /ac/00/backgrd/3634bla tab5b.htm (accessed 2010 Nov. 25).

5. Drug safety and availability: Trovan (trovafloxacin/alatrofloxacin mesylate). Silver Spring (MD): Food and Drug Administration;1999. Available: www.fda.gov/Drugs/DrugSafety/Postmarket DrugSafetyInformationforPatientsandProviders/DrugSafety InformationforHeathcareProfessionals/PublicHealthAdvisories /UCM053103 (accessed 2010 Nov. 25).

6. Notice: Determination that Tequin (gatifloxacin) was withdrawn from sale for reasons of safety or effectiveness. Silver Spring 
(MD): US Food and Drug Administration; 2008. Available: http://edocket.access.gpo.gov/2008/pdf/E8-20938.pdf (accessed 2010 Nov. 25).

7. Van Bambeke F, Tulkens PM. Safety profile of the respiratory fluoroquinolone moxifloxacin: comparison with other fluoroquinolones and other antibacterial classes. Drug Saf 2009;32:359-78

8. European Medicines Agency recommends restricting the use of oral moxifloxacin containing medicines [news release]. London (UK): European Medicines Agency; 2008. Available: www.ema .europa.eu/ema/index.jsp?curl=pages/news_and_events/news/2010 /08/news_detail_001068.jsp\&mid=WC0b01ac058004d5c1\&murl $=$ menus/news_and_events/news_and_events.jsp\&jsenabled $=$ true (accessed 2010 Nov. 24)

9. Health Canada. Updated labelling for antibiotic Avelox (moxifloxacin) regarding rare risk of severe liver injury information update. Ottawa $(\mathrm{ON})$ : Health Canada; 2010. Available: www.hc -sc.gc.ca/ahc-asc/media/advisories-avis/_2010/2010_42-eng.php (accessed 2012 July 30).

10. Southern DA, Faris PD, Knudtson ML, et al. Prognostic relevance of census-derived individual respondent incomes versus household incomes. Can J Public Health 2006;97:114-7.

11. Levy AR, O'Brien BJ, Sellors C, et al. Coding accuracy of administrative drug claims in the Ontario Drug Benefit database. Can J Clin Pharmacol 2003;10:67-71.

12. Williams JI, Young W. A summary of studies on the quality of health care administrative databases in Canada. In: Goel V, Williams JI, Anderson GM, et al., editors. Patterns of health care in Ontario, the ICES practice atlas. 2nd ed. Ottawa (ON): Canadian Medical Association; 1996. p. 339-45.

13. Juurlink DN, Mamdani MM, Lee DS, et al. Rates of hyperkalemia after publication of the Randomized Aldactone Evaluation Study. N Engl J Med 2004;351:543-51.

14. Juurlink DN, Gomes T, Lipscombe LL, et al. Adverse cardiovascular events during treatment with pioglitazone and rosiglitazone: population-based cohort study. BMJ 2009;339:b2942.

15. Park-Wyllie LY, Mamdani MM, Juurlink DN, et al. Bisphosphonate use and the risk of subtrochanteric or femoral shaft fractures in older women. JAMA 2011;305:783-9.

16. Canadian Institute for Health Information. International Statistical Classification of Diseases and Related Health Problems, 10th Revision, Canadian Enhancement. Canadian Institute for Health Information; 2009.

17. Myers RP, Leung Y, Shaheen AA, et al. Validation of ICD-9$\mathrm{CM} / \mathrm{ICD}-10$ coding algorithms for the identification of patients with acetaminophen overdose and hepatotoxicity using administrative data. BMC Health Serv Res 2007; 7:159.

18. Hoofnagle JH. Drug-induced liver injury network (DILIN). Hepatology 2004:40:773.

19. Chalasani N, Fontana RJ, Bonkovsky HL, et al. Causes, clinical features, and outcomes from a prospective study of druginduced liver injury in the United States. Gastroenterology 2008 135:1924-34, 1934.e1-4.

20. Schneeweiss S, Maclure M. Use of comorbidity scores for control of confounding in studies using administrative databases. Int J Epidemiol 2000;29:891-8.

21. Brinker A. Telithromycin-associated hepatotoxicity. Presentation to the FDA Joint Meeting of the Anti-Infective Drugs Advisory Committee and the FDA Drug Safety and Risk Management Committee; 2006 Dec. 14-15. Available: www.fda.gov/ohrms /dockets/ac/06/slides/2006-4266s1-01-07-FDA-Brinker.ppt\#256,1 (accessed 2012 July 30).

22. Rullo B. Hepatic safety experience. Silver Spring (MD): US Food and Drug Administration Advisory Committee; 2006. Available: www.fda.gov/ohrms/dockets/ac/06/slides/2006-4266s1-02-07-\%20 Ketek-Rullo.pdf (accessed 2010 Nov. 25)

23. Zimpfer A, Propst A, Mikuz G, et al. Ciprofloxacin-induced acute liver injury: case report and review of literature. Virchows Arch 2004;444:87-9.

24. Verma R, Dhamija R, Batts DH, et al. Moxifloxacin induced fatal hepatotoxicity in a 72-year-old man: a case report. Cases J 2009, $2: 8063$
25. Orman ES, Conjeevaram HS, Vuppalanchi R, et al.; DILIN Research Group. Clinical and histopathologic features of fluoroquinolone-induced liver injury. Clin Gastroenterol Hepatol 2011;9:517-23.

26. Andrade RJ, Lucena MI, Fernandez MC, et al. Drug-induced liver injury: an analysis of 461 incidences submitted to the Spanish registry over a 10-year period. Gastroenterology 2005;129: 512-21.

27. Zimmerman H. Hepatotoxicity: the adverse effects of drugs and other chemicals on the liver. 2nd ed. Philadelphia (PA): Lippincott Williams \& Wilkins; 1999.

28. Lewis JH. The rational use of potentially hepatotoxic medications in patients with underlying liver disease. Expert Opin Drug Saf 2002;1:159-72.

29. Russo MW, Watkins PB. Are patients with elevated liver tests at increased risk of drug-induced liver injury? Gastroenterology 2004; $126: 1477-80$.

30. Chalasani N, Bjornsson E. Risk factors for idiosyncratic druginduced liver injury. Gastroenterology 2010;138:2246-59.

Affiliations: From the Institute for Clinical Evaluative Sciences (Paterson, Mamdani, Manno, Juurlink), Toronto, Ont.; The Sunnybrook Research Institute (Juurlink), Toronto, Ont; the Departments of Medicine (Juurlink) and Health Policy, Management, and Evaluation (Paterson), and the Leslie Dan Faculty of Pharmacy (Mamdani), University of Toronto, Toronto, Ont.; Keenan Research Centre of the Li Ka Shing Knowledge Institute (Mamdani), St. Michael's Hospital, Toronto, Ont.; and the Department of Family Medicine (Paterson), McMaster University, Hamilton, Ont.

Contributors: J. Michael Paterson and Michael Manno had full access to all of the data and take responsibility for the integrity of the data and the accuracy of its analysis. J. Michael Paterson, David Juurlink and Muhammad Mamdani were responsible for the study's concept and design. J. Michael Paterson and Michael Manno acquired the data. All of the authors analyzed and interpreted the data. J. Michael Paterson drafted the manuscript. All of the authors critically revised the manuscript for important intellectual content and approved the final version submitted for publication. David Juurlink supervised the study.

Funding: This study was supported by a grant from the Canadian Institutes of Health Research (CIHR). CIHR had no role in designing the study; collecting, analyzing, or interpreting the data; writing the report; or in the decision to submit the article for publication.

Disclaimer: This study was supported by the Institute for Clinical Evaluative Sciences (ICES), which is funded by an annual grant from the Ontario Ministry of Health and Long-Term Care (MOHLTC). The opinions, results and conclusions reported in this paper are those of the authors and are independent from the funding sources. No endorsement by ICES or the Ontario MOHLTC is intended or should be inferred.

Acknowledgement: The authors thank Brogan Inc., Ottawa, Ontario, for the use of their Drug Product and Therapeutic Class Database.

Members of the Canadian Drug Safety and Effectiveness Research Network: J. Michael Paterson, Muhammad M. Mamdani, Michael Manno, David N. Juurlink, Colin Dormuth, Anita Kozyrskyj, Colette Raymond, Robyn Tamblyn, and Yola Moride. 